\title{
ABL Kinase Domain Mutations in Patients with Chronic Myeloid Leukemia in Jordan
}

\author{
Abdalla Awidi, Nidaa Ababneh, ${ }^{2}$ Ahmad Magablah, ${ }^{3}$ Nazzal Bsoul, ${ }^{3}$ Razan Mefleh, \\ Lina Marei, ${ }^{4}$ and Salah Abbasi ${ }^{4}$
}

Mutations of the $B C R-A B L$ tyrosine kinase domain constitute a major cause of resistance to tyrosine kinase inhibitors in patients with chronic myelogenous leukemia (CML). In this study, we analyzed peripheral blood samples from 185 Jordanian CML patients for ABL mutations, who were on imatinib for a minimum of 6 months regardless of their disease status and over a period of 5 years. Mutations were detected by nested RTpolymerase chain reaction, followed by direct sequencing of the ABL kinase domain. Twelve different point mutations were detected 25 times in 21 patients. The resultant mutations were as follows: four patients have T315I, three of each of the following: L248V, F317L, and G250E, two of each of the following: H396R, M244V, and T277A, and one of each of the following: F311I, M318T, Q252H, F359A, F359I, and Y326H. After patient follow-up, the mutation had disappeared in 12 patients; 3 patients died; 3 patients were not retested; and 3 patients had persistent mutation. The finding of our study is in line with what has been described in the literature. Detecting ABL mutations in chronic phase may lead to positive outcome by modifying treatment.

\section{Introduction}

C HRONic MYelogenous leuKemia (CML) is a clonal myeloproliferative neoplasm; it is characterized by the presence of the Philadelphia chromosome (Ph1) which is the product of the $\mathrm{t}(9 ; 22)$ ( $\mathrm{q} 34 ; \mathrm{q} 11)$ translocation (Mauro and Druker, 2001). This translocation results in the $B C R-A B L$ gene and the fusion protein that has constitutive tyrosine kinase activity. CML progresses from a relatively benign chronic phase $(\mathrm{CP})$ to an accelerated phase that is characterized by increasing numbers of early hematopoietic cells and additional chromosomal abnormalities (Branford and Hughes, 2006). The disease terminates in blast crisis (BC), which is distinguished by the large number of immature blast cells that populate the bone marrow and peripheral blood (Branford et al., 2006).

Successful development of the BCR-ABL tyrosine kinase inhibitor (TKIs) imatinib for chronic myeloid leukemia (CML) marked the beginning of the era in targeted therapy of CML (Maekawa et al., 2007). Over the last decade, imatinib has been the standard of care for CML (Maekawa et al., 2007). Imatinib is able to induce a major cytogenetic response in the majority of CP CML patients (Sawyers et al., 2002). Eighty-five percent of patients treated with imatinib attained a major cytogenetic response after a median follow-up of 19 months, compared to $22 \%$ of patients treated with a nonimatinib combination (Kantarjian et al., 2002). Mutations of the BCR-ABL tyrosine kinase domain constitute the major cause of resistance to TKIs in patients with chronic myeloid leukemia occurring in $30 \%$ to $90 \%$ of patients who develop resistance (Cortes et al., 2007; Ray et al., 2007). Mutations in more than 40 different amino acids have been described, conferring differing levels of resistance to imatinib (Cortes et al., 2007). CP CML patients may develop BCR-ABL point mutations after starting the treatment, while others, almost exclusively patients in more advanced phases of the disease, may present mutations already at diagnosis (Luzzatto and Melo, 2002; Roche-Lestienne et al., 2002). Using highly sensitive detection techniques, mutations can be seen even in CP CML patients at diagnosis, but their clinical significance is uncertain. Most resistant patients have acquired point mutations in the ABL kinase domain that render the kinase resistant to imatinib (Melo and Chuah, 2007). Early detection of $B C R-A B L$ mutants may identify patients who are likely to become resistant to imatinib therapy (Kantarjian et al., 2008).

All patients with chronic myeloid leukemia on treatment should be monitored by cytogenetics using karyotyping or FISH techniques or with quantitative RT-polymerase chain

\footnotetext{
${ }^{1}$ Thrombosis and Molecular Hematology Laboratory (TMHL), Department of Medicine and Hematology, Faculty of Medicine, University of Jordan, Amman, Jordan.

${ }^{2}$ Molecular Biology Research Laboratory, University of Jordan, Amman, Jordan.

${ }^{3}$ Department of Internal Medicine, Al-Bashir Hospital, Amman, Jordan.

${ }^{4}$ Department of Medical Oncology, King Hussein Cancer Center (KHCC), Amman, Jordan.
} 
reaction (PCR) (Kantarjian et al., 2002; Reinhold et al., 2003). The resistance testing is useful to help guide CML treatment with alternative therapies (O'Hare et al., 2007). Depending on the exact mutation present, clinical intervention such as increasing dosage of imatinib or using other kinase inhibitors may be effective in controlling the levels of BCR-ABL and the relapse of the disease. Hematopoietic stem cell transplantation may also be an option to be taken into consideration in the presence of specific mutations, such as the T315I mutation, which has been shown to be insensitive to all registered TKIs (Velev et al., 2010).

The aim of this study was to identify ABL mutations in CML patients in a developing country followed for a long period and report on the outcome of the patients developing clones with these mutations.

\section{Materials and Methods}

\section{Patients}

A total of 185 CML patients who were on imatinib treatment for at least of 6 months regardless of their disease status and who were either followed at the Jordan University Hospital or referred to the Thrombosis and Molecular Hematology Laboratory (TMHL) for real-time quantitative PCR (RQ-PCR) for BCR-ABL transcripts were screened for ABL mutations. The diagnosis of CML was based on cytogenetics, FISH, or molecular method. The study was approved by the investigational review board, and a consent form was obtained from each patient in accordance with the Helsinki declaration. Seventy-six patients were women with a median age of $53.00 \pm 12.00$ years, and 109 of patients were men with a median age of $58.00 \pm 2.00$ years as shown in Table 1 . The median of age for patients with ABL mutations was $47.3 \pm 16$ for women $(n=7)$ and $43.9 \pm 20$ for men $(n=14)$. All patients were in $\mathrm{CP}$, except two were in $\mathrm{AP}$ and one in $\mathrm{BC}$.

The mean duration of disease in the whole population was $93.4 \pm 16$ months, and the mean duration of disease in patients with ABL mutations $(n=21)$ was $37.44 \pm 12.00$ months. Blood samples were collected between February 2006 and September 2011. The 21 patients with mutations were monitored for disease status for a median of $22.0 \pm 12.4$ months after initial detection of the mutation. All patients were on imatinib for a minimum of six months. The initial dose of imatinib was $400 \mathrm{mg} /$ day in the patients with CP CML and $800 \mathrm{mg} /$ day in those with accelerated phase. The mean dose of imatinib in all population was $388.53 \pm 55.00 \mathrm{mg} /$ day among women $(n=76)$ and $390.39 \pm 65.00 \mathrm{mg} /$ day among men $(n=109)$ as shown in Table 1 . The mean dose of imatinib among patients with ABL mutations was $365 \pm 65 \mathrm{mg} /$ day for females $(n=7)$ and $367 \pm 65 \mathrm{mg} /$ day for males $(n=14)$.

All 21 patients with mutations were in $\mathrm{CP}$, except 1 who was in BC. Four patients failed to achieve hematologic response, and 17 patients achieved complete hematologic response. Nine patients failed to achieve major molecular response, and 11 patients failed to achieve complete cytogenetic response (CCYR) as shown in Table 4. Monitoring included peripheral blood counts, bone marrow morphology, metaphase karyotyping of bone marrow cells, interphase FISH (bone marrow samples only), and RQ-PCR for quantitation of BCR-ABL transcripts using bone marrow and blood samples.
Table 1. Duration of Chronic Myelogenous Leukemia And Dose of Imatinib for All Populations $(N=185)$

\begin{tabular}{lccc}
\hline Gender & $\begin{array}{c}\text { Mean } \\
\text { age } \\
\text { (year) }\end{array}$ & $\begin{array}{c}\text { Mean duration } \\
\text { of CML } \\
\text { (months) }\end{array}$ & $\begin{array}{c}\text { Mean } \\
\text { dose of } \\
\text { imatinib }\end{array}$ \\
\hline F $(n=76)$ & $53.00 \pm 12.00$ & $83.3 \pm 22$ & $388.53 \pm 55.00$ \\
M $(n=109)$ & $58.00 \pm 2.00$ & $98.6 \pm 12$ & $390.39 \pm 65.00$ \\
Total $(n=185)$ & $56.00 \pm 5.00$ & $93.4 \pm 16$ & $389.57 \pm 58.00$
\end{tabular}

CML, chronic myelogenous leukemia.

\section{RNA extraction and cDNA synthesis}

Total RNA was extracted from peripheral blood leukocytes using TRIzol reagent (Life Technologies) according to the manufacturer's instructions. cDNA was synthesized from $1 \mu \mathrm{g}$ total RNA in a $20-\mu \mathrm{L}$ reaction mixture using random hexamer primers and MMLV reverse transcriptase superscript III enzyme (Invitrogen ${ }^{\mathrm{TM}}$ ).

\section{$B C R-A B L$ quantitation}

The quality of the RNA was assessed before sequencing by measurement of the level of BCR-ABL and normal ABL transcripts using RQ-PCR (Kantarjian et al., 2003; Hughes and Branford, 2006). A cut-off level based on the number of detectable $A B L$ gene transcripts in the $B C R-A B L$ cDNA that was quantified by the real-time PCR technique using a Fusion Quant kit (Ipsogen, Inc.) for quantitation of BCR-ABL fusion gene transcripts with normalization to total ABL gene levels according to the manufacturer instructions.

\section{PCR amplification and mutation analysis}

The ABL kinase domain of the BCR-ABL fusion gene was amplified using nested RT-PCR, followed by direct sequencing as described previously (Sacha et al., 2003). Briefly, the $B C R-A B L$ allele was amplified using a forward primer that annealed to the BCR exon $b 2$ and a reverse primer that annealed to the exon 7 of the ABL gene. A 675-bp fragment containing the BCR-ABL kinase domain was amplified using a nested PCR, and then the PCR amplification was confirmed by agarose gel electrophoresis and sequenced in both directions to confirm the presence of the mutations using Dye Terminator Chemistry and an ABI 3310 genetic analyzer (Applied Biosystems). The amino acid substitutions were determined using the GenBank accession no. M14752. The sequencing reactions were repeated for confirmation of the positive results.

Table 2. Duration of Chronic Myelogenous LEUKEMIA AND DOSE OF IMATINIB FOR THE (21) Patients with Mutations

\begin{tabular}{lcrr}
\hline Gender & $\begin{array}{c}\text { Mean age } \\
\text { (year) }\end{array}$ & $\begin{array}{c}\text { Mean } \\
\text { duration of } \\
\text { CML (months) }\end{array}$ & $\begin{array}{c}\text { Mean } \\
\text { dose of } \\
\text { imatinib }\end{array}$ \\
\hline $\mathrm{F}(n=7)$ & $47.3 \pm 16$ & $30.25 \pm 17.00$ & $365.00 \pm 25.00$ \\
$\mathrm{M}(n=14)$ & $46.81 \pm 17.15$ & $35.4 \pm 15.00$ & $367.40 \pm 65.00$ \\
Total $(n=21)$ & $44.75 \pm 18.2$ & $34.6 \pm 16.00$ & $366.26 \pm 53.00$ \\
\hline
\end{tabular}


TABle 3. Type AND FReQuency of 25 ABL Kinase Domain Mutations

\begin{tabular}{lc}
\hline Mutation & No. of patients \\
\hline M244V & 2 \\
L248V & 3 \\
G250E & 3 \\
Q252H & 1 \\
T277A & 2 \\
F311I & 1 \\
T315I & 4 \\
F317L & 3 \\
M318T & 1 \\
Y326H & 1 \\
F359A & 1 \\
F359I & 1 \\
H396R & 2 \\
\hline
\end{tabular}

\section{Results}

Mutations were observed in 21 patients of the analyzed population (185). Tables 1 and 2 shows the duration of CML and the dose of imatinib for all 185 study patients and for the patients with mutations, respectively, Table 3 shows the types and frequencies of ABL kinase domain mutations, and Table 4 shows the disease outcome of patients with ABL mutations after a mean follow-up of $22 \pm 12.4$ months. The mean duration of disease for 185 patients was $83.3 \pm 22.00$ for women $(n=76)$ and $98.6 \pm 12.00$ for men $(n=109)$ as shown in Table 1. The mean duration of CML for patients with mutations $30.25 \pm 17$ for women $(n=7)$ and was $35.4 \pm 15$ months for men $(n=14)$ as shown in Table 2 . Twelve different point mutations were detected 25 times (13.51\%) in 21/185 patients $(11.35 \%) ; 4$ patients have T315I; 3 patients have L248V; 3 patients have G250E; and 3 have F317L; two patients with each of the following mutations: M244V, T277A, and H396R, and one patient with each of the following mutations: M318T, Y326H, Q252H, F311I, F359A, and F359I. Three of the above 21 patients had more than one mutation, one of them had M244V with G250E; the second patient had F317L, M318T, and $\mathrm{Y} 326 \mathrm{H}$, and the third one had T277A and F359A as listed in Table 4.

\section{Discussion}

In this study, we intended to test patients who had received at least 6 months of imatinib regardless of the disease status.

Table 4. Disease Outcome of the 21 Patients with Mutations

\begin{tabular}{|c|c|c|c|c|c|c|}
\hline $\begin{array}{l}\text { Patient } \\
\text { No. }\end{array}$ & $\begin{array}{l}\text { Agel } \\
\text { sex }\end{array}$ & $\begin{array}{c}\text { Response } \\
\text { by } 6 \\
\text { months }\end{array}$ & CML phase & Mutation onset & $\begin{array}{l}\text { Treatment strategy after } \\
\text { mutation detection }\end{array}$ & $\begin{array}{l}\text { Follow-up } \\
\text { analysis }\end{array}$ \\
\hline 1 & $72 / \mathrm{M}$ & $\mathrm{CP}$ & Loss of CCYR & M244V G250E & Nilotinib & G250E \\
\hline 2 & $32 / \mathrm{M}$ & $\mathrm{CP}$ & Loss of CCYR & L248V & $\begin{array}{l}\text { Imatinib dose increased } \\
\text { to } 800 \mathrm{mg} / \text { day }\end{array}$ & Negative \\
\hline 3 & $35 / \mathrm{M}$ & $\mathrm{CP}$ & Loss of CCYR & L248V & Nilotinib & Negative \\
\hline 4 & $59 / \mathrm{F}$ & $\mathrm{CP}$ & Loss of CCYR & F311I & Nilotinib & Negative \\
\hline 5 & $50 / \mathrm{M}$ & $\mathrm{BC}$ & Loss of CCYR & T315I & Hydroxyurea & Died \\
\hline 6 & $31 / \mathrm{M}$ & $\mathrm{CP}$ & Loss of CCYR & T315I & Hydroxyurea & Not retested $^{\mathrm{a}}$ \\
\hline 7 & $29 / \mathrm{M}$ & $\mathrm{CP}$ & Loss of CCYR & L248V & $\begin{array}{l}\text { Imatinib dose increased } \\
\text { to } 800 \mathrm{mg} / \text { day }\end{array}$ & Negative \\
\hline 8 & $70 / \mathrm{M}$ & $\mathrm{CP}$ & Loss of CCYR & F317L M318T Y326H & $\begin{array}{l}\text { Imatinib dose increased } \\
\text { to } 800 \mathrm{mg} / \text { day }\end{array}$ & Negative \\
\hline 9 & $48 / \mathrm{F}$ & $\mathrm{CP}$ & Loss of CCYR & H396R & Dasatinib & Negative \\
\hline 10 & $77 / \mathrm{M}$ & $\mathrm{CP}$ & Loss of MMR & $\mathrm{M} 244 \mathrm{~V}$ & $\begin{array}{l}\text { Imatinib dose increased } \\
\text { to } 600 \mathrm{mg} / \text { day }\end{array}$ & M244V \\
\hline 11 & $72 / \mathrm{M}$ & $\mathrm{CP}$ & Loss of MMR & G250E & Dasatinib & Died \\
\hline 12 & $45 / \mathrm{M}$ & $\mathrm{CP}$ & Loss of MMR & H396R & $\begin{array}{l}\text { Imatinib dose increased } \\
\text { to } 800 \mathrm{mg} / \text { day }\end{array}$ & Negative \\
\hline 13 & $26 / \mathrm{M}$ & $\mathrm{CP}$ & Loss of CCYR & F317L & $\begin{array}{l}\text { Imatinib dose increased } \\
\text { to } 800 \mathrm{mg} / \text { day }\end{array}$ & Negative \\
\hline 14 & $32 / \mathrm{M}$ & $\mathrm{CP}$ & Loss of MMR & Q252H & $\begin{array}{l}\text { Imatinib dose increased } \\
\text { to } 800 \mathrm{mg} / \text { day }\end{array}$ & Negative \\
\hline 15 & $42 / \mathrm{F}$ & $\mathrm{CP}$ & Loss of MMR & T277A & $\begin{array}{l}\text { Imatinib dose increased } \\
\text { to } 800 \mathrm{mg} / \text { day }\end{array}$ & $\mathrm{T} 277 \mathrm{~A}$ \\
\hline 16 & $59 / \mathrm{F}$ & $\mathrm{CP}$ & Loss of MMR & F317L & Nilotinib & Negative \\
\hline 17 & $50 / \mathrm{F}$ & $\mathrm{CP}$ & Loss of MMR & T315I & Nilotinib & Not retested ${ }^{a}$ \\
\hline 18 & $31 / \mathrm{M}$ & $\mathrm{CP}$ & Loss of MMR & T277A F359A & $\begin{array}{l}\text { Imatinib dose increased } \\
\text { to } 800 \mathrm{mg} / \text { day }\end{array}$ & Died \\
\hline 19 & $23 / \mathrm{F}$ & $\mathrm{CP}$ & Loss of CCYR & F359I & Nilotinib & Negative \\
\hline 20 & $36 / \mathrm{M}$ & $\mathrm{CP}$ & Loss of MMR & G250E & $\begin{array}{l}\text { Imatinib dose increased } \\
\text { to } 800 \mathrm{mg} / \text { day }\end{array}$ & Negative \\
\hline 21 & $18 / \mathrm{M}$ & $\mathrm{CP}$ & Loss of CCYR & T315I & Dasatinib & Not retested ${ }^{a}$ \\
\hline
\end{tabular}

${ }^{a}$ Reason for not retesting: in two patients the follow-up was less than 6 months, and one patient was lost to follow-up. $\mathrm{CP}$, chronic phase; $\mathrm{BC}$, blast crisis, CHR, complete hematologic response, FHR, failure of hematologic response; MMR, major molecular response; CCYR, complete cytogenetic response. 
The samples were initially assessed for the level of $B C R-A B L$ and only preceded to mutation analysis if the stored RNA contained a measurable level of $B C R-A B L$, and the control gene level was indicated. Patients tested had either received 6 or more months of imatinib therapy or had developed resistance and ceased therapy after having received imatinib treatment.

The degree of resistance depends on the mutation, with some mutations remaining sensitive to imatinib (Jabbour and Soverini, 2009). Dose escalation of imatinib may overcome resistance in some of these patients. Patients with some mutations may be sensitive to therapy with second-generation TKIs such as nilotinib or dasatinib (Weisberg et al., 2007). The choice of therapy should be guided by multiple factors, including disease phase, patient characteristics, mutational analysis, and the safety profile of the agents (Jabbour et al., 2009).

Current evidence does not support mutation screening on a routine basis unless there is an indication such as loss of response (An et al., 2010). Transient detection of kinase domain mutations has been documented in some patients with stable CCYR, suggesting that the detection of a mutation in the absence of an increase in leukemia burden is uninterpretable (Sherbenou et al., 2007).

Despite the fact that our patients were followed for many years from the diagnosis of CML and for several months after ABL mutation detection, further follow-up is needed to identify the course of the ABL mutation and outcome of these patients. Follow-up for patients with ABL mutations were as follows: the mutations disappeared in 12 patients; 7 patients after the Imatinib dose was increased to $800 \mathrm{mg} /$ day; 2 of them had L248V, 1 patient with each of the following H396R, F317L, G250E, and Q252H, and 1 patient with three mutations F317L, M318T, and Y326H. In four patients after Nilotinib was given, one patient of each of the following mutations: L248V, F311I, F317L and F359I, and in one patient with H396R after Dasatinib was given as shown in Table 4 . Three patients were still having the mutation after treatment change: one with T277A mutation, one with G250E mutation and one with M244V mutation. Three patients died, two of them due to disease progression. Three patients were not retested; two of them because of a less-than 6-month follow-up and one patient were lost at follow-up.

In this study, we found three patients with more than one mutation. Patient number 1 and 18 each had two mutations, and patient number 8 had three different point mutations. In patient 18 , the mutations conferred a total resistance to imatinib, since it did not respond to increasing the imatinib dose, and subsequently, the patient transformed to acute myeloid leukemia and died. It is possible that these mutations have conferred a gain of function and a second generation of TKIs may overcome this issue. In patient number 1 , the mutation seems to be responsive to Nilotinib, since it disappeared after Nilotinib therapy. While in patient Number 8 , the mutations have disappeared 2 years after continuous therapy with increased dose of imatinib. We are not aware that such a combination of three mutations has been reported.

The finding of our study concerning $A B L$ gene mutation in CML is in line with what has been described in the literature (Soverini et al., 2006; Lewandowski et al., 2009). Mutations were found in 21 of 185 chronic-phase patients $(11.35 \%)$ treated with imatinib with L248V, G250E, and T315I, being the more frequently seen. ABL Mutations in our study were widely distributed on the ABL gene as described in a previous study (Markose et al., 2009). We found no cluster of CML in any family.

Detecting ABL mutations in CP may lead to positive outcome by modifying treatment. The screening of ABL mutation is not recommended routinely for patients with CML, but rather it should be limited to a selected group of patients who have a poor or suboptimal response or a loss of CCYR or an increase of BCR-ABL transcript (Sherbenou et al., 2007). Mutation analysis in this situation might influence the course of disease and therapy. Resistance to imatinib may be caused by factors other than ABL mutation. This work did not explore this aspect, since we looked at ABL mutations only. Future work will be directed toward this aspect.

\section{Acknowledgment}

The authors wish to thank Professor Giuseppe Saglio for reviewing the manuscript. The authors are grateful for the financial support provided by the Deanship of Scientific Research of Jordan University, Grant No. 1147 and 1211.

\section{Author Disclosure Statement}

None of the authors have any conflicts of interest regarding this publication.

\section{References}

An X, Tiwari AK, Sun Y, et al. (2010) BCR-ABL tyrosine kinase inhibitors in the treatment of Philadelphia chromosome positive chronic myeloid leukemia: a review. Leuk Res 34:1255-1268.

Branford S, Hughes T (2006) Detection of BCR-ABL mutations and resistance to imatinib mesylate. Methods Mol Med 125: 93-106.

Cortes J, Jabbour E, Kantarjian H, et al. (2007) Dynamics of BCR/ ABL kinase domain mutations in chronic myeloid leukemia after sequentialtreatment with multiple tyrosine kinase inhibitors. Blood 110:4005-4011.

Hughes T, Branford S (2006) Molecular monitoring of BCR-ABL as a guide to clinical management in chronic myeloid leukemia. Blood Rev 20:29-41.

Jabbour E, Soverini S (2009) Understanding the role of mutations in therapeutic decision making for chronic myeloid leukemia. Semin Hematol 46(2 Suppl 3):S22-S26.

Kantarjian H, Sawyers C, Hochhaus A, et al. (2002) Hematologic and cytogentic responses to imatinib mesylate in chronic myelogenous leukemia. N Engl J Med 346:645-652.

Kantarjian H, Schiffer C, Jones D, et al. (2008) Monitoring the response and course of chronic myeloid leukemia in the modern era of BCR-ABLtyrosine kinase inhibitors: practical advice on the use and interpretation of monitoring methods. Blood 111:1774-1780.

Kantarjian HM, Talpaz M, Cortes J, et al. (2003) Quantitative polymerase chain reaction monitoring of BCR-ABL during therapy with imatinib mesylate (STI571; gleevec) in chronic phase chronic myelogenous leukemia. Clin Cancer Res 9:160-166.

Lewandowski K, Warzocha K, Hellmann A, et al. (2009) Frequency of BCR-ABL gene mutations in Polish patients with chronic myeloid leukemia treatedwith imatinib: a final report of the MAPTEST study. Pol Arch Med Wewn 119:789-794.

Luzzatto L, Melo JV (2002) Acquired resistance to Imatinib mesylate: selection for pre-existing mutant cells. Blood 100:1105. 
Maekawa T, Ashihara E, Kimura S (2007) The Bcr-Abl tyrosine kinase inhibitor imatinib and promising new agents against Philadelphia chromosome-positive leukemias. Int J Clin Oncol 12:327-340.

Markose P, Chendamarai E, Balasubramanian P, et al. (2009) Spectrum of BCR-ABL kinase domain mutations in patients with chronic myeloid leukemia from India with suspected resistance to imatinib-mutations are rare and have different distributions. Leuk Lymphoma 50:2092-2095.

Mauro MJ, Druker BJ (2001) Chronic myelogenous leukemia. Curr Opin Oncol 13:3-7.

Melo JV, Chuah C (2007) Resistance to imatinib mesylate in chronic myeloid leukaemia. Cancer Lett 249:121-132.

O'Hare T, Eide CA, Deininger MW (2007) Bcr-Abl kinase domain mutations, drug resistance, and the road to a cure for chronic myeloid leukemia. Blood 110:2242-2249.

Ray A, Cowan-Jacob SW, Manley PW, et al. (2007) Identification of BCR-ABL point mutations conferring resistance to the $\mathrm{Abl}$ kinase inhibitor AMN107 (nilotinib) by a random mutagenesis study. Blood 109:5011-5015.

Reinhold U, Hennig E, Leiblein S, et al. (2003) FISH for BCR-ABL on interphases of peripheral blood blood neutrophils but not of unselected white cells correlates with bone marrow cytogenetics in CML patients treated with imatinib. Leukemia 17:1925-1929.

Roche-Lestienne C, Soenen-Cornu V, Grardel-Duflos N, et al. (2002) Several types of mutation of the Abl gene can be found in chronic myeloid leukemia patients resistant to STI571 and they can pre-exist to the onset of treatment. Blood 100: 1014-1018.

Sacha T, Hochhaus A, Hanfstein B, et al. (2003) ABL-kinase domain point mutation as a cause of imatinib (STI571) resistance in CML patient who progress to myeloid blast crisis. Leuk Res 27:1163-1166.
Sawyers CL, Hochhaus A, Feldman E, et al. (2002) Imatinib induces hematologic and cytogenetic responses in patients with chronic myelogenous leukemia in myeloid blast crisis: results of a phase II study. Blood 99:3530-3539.

Sherbenou DW, Wong MJ, Humayun A, et al. (2007) Mutations of the BCR-ABL-kinase domain occurs in a minority of patients with stable complete cytogenetic response to imatinib. Leukemia 21:489-493.

Soverini S, Colarossi S, Gnani A, et al. (2006) Contribution of ABL kinase domain mutations to imatinib resistance in different subsets of Philadelphia-positive patients: by the GIMEMA Working Party on Chronic Myeloid Leukemia. Clin Cancer Res 12:7374-7379.

Velev N, Cortes J, Champlin R, et al. (2010) Stem cell transplantation for patients with chronic myeloid leukemia resistant to tyrosine kinaseinhibitors with BCR-ABL Kkinase domain mutation T315I. Cancer 116:3631-3637.

Weisberg E, Manley PW, Cowan-Jacob SW, et al. (2007) Second generation inhibitors of $\mathrm{BCR}-\mathrm{ABL}$ for the treatment of imatinib-resistant chronic myeloid leukaemia. Nat Rev Cancer 7:345-356.

Address correspondence to: Abdalla Awidi

Thrombosis and Molecular Hematology Laboratory (TMHL) Department of Medicine and Hematology

Faculty of Medicine

University of Jordan

Amman 11942

Jordan

E-mail: abdalla.awidi@gmail.com 